\title{
Effects of High pressure coolant on machining temperature and machinability of AISI 304 stainless steel
}

\author{
Yassmin Seid Ahmed ${ }^{1}$, Stephen Clarence Veldhuis ${ }^{2}$ \\ McMaster Manufacturing Research Institute (MMRI), Department of Mechanical Engineering, McMaster University \\ Hamilton, Canada \\ ${ }^{1}$ Seidahmy@mcmaster.ca \\ 2veldhu@mcmaster.ca
}

\begin{abstract}
Effective zones of high pressure coolant (HPC) have been identified in turning performing a wide range of machining operations on 304 stainless steel using uncoated carbide inserts. The effects of triple coolant jets on tool-chip interface temperature were studied. In addition, their performance are evaluated in terms of machining parameters by comparing with those of conventional coolant and dry cut. Chipping and catastrophic failure are the dominant factors of insert rejection for dry cut and conventional coolant, whereas progressive flank wear is observed for HPC within its effective zones at lower feed rate and higher cutting speed. It is found that the cutting force is reduced, surface finish is improved, chip width is narrowed and cooling effect is better with the use of HPC. The enhanced heat dissipation by triple jets is accredited as the primary reason for the reduction of cutting forces, surface roughness and tool wear.
\end{abstract}

Keywords-high pressure coolant; 304 stainless steel; tool wear; cutting forces; chip formation; surface roughness

\section{INTRODUCTION}

Machining is a manufacturing process where a sharp cutting tool penetrates the surface of a work material. The penetration causes shear deformation of the workpiece in order to remove material from the surface in the form of chips. During the formation of chips, the mechanical energy applied by the insert converts to heat energy [1]. Plastic deformation of the work material and friction between tool rake face, and flowing chips foster intense amount of heat at the cutting zone [2]. Machining of stainless steel and other difficult to cut materials requires instant heat transfer from the cutting edge of tool to aid tool life. Supply of high volume and HPC often provides the best answer. Conventional coolant does not reach the real cutting area near the cutting edge of the tool and vaporizes before it reaches the cutting area as the heat is very intense during machining [3]. 304 stainless steel is mainly used for Heat Exchangers, bushings, springs, bearings, gears, and shafts. Despite the increased usage of 304 stainless steel, they have relatively poor machinability characteristics compared to other metals, because of their poor thermal conductivity [4].
They are very difficult to machine and intense amount of heat generates during machining which must be reduced to enhance product quality and dimensional accuracy by proper application of coolant [5].

The concept of HPC may be a possible solution for high speed machining in achieving intimate chip-tool interaction, low cutting temperature and slow tool wear while maintaining cutting forces at reasonable levels. [6] Based on the necessity and versatility of HPC in machining, this study focuses on the machinability assessment of AISI 304 stainless steel by using uncoated carbide inserts at dry, conventional coolant, and triple jets HPC lubrication. The evaluation of HPC has been executed in two steps: firstly, based on the ability of HPC to reduce the cutting temperature, and secondly, the relevance of this temperature lowering with favorable curbing of the cutting force, tool wear, surface quality, and chip formation.

\section{EXPERIMENTAL PARAMETERS AND PROCEDURES}

In this research, a round bar $(120 \mathrm{~mm}$ diameter by $500 \mathrm{~mm}$ length) of an austenitic stainless steel AISI 304 was investigated during turning. The chemical composition of the material is shown in Table 1. To reveal the workpiece microstructure, a sample of the AISI 304 was prepared, polished and etched with Glycergia solution (1 mL Glycerol + $20 \mathrm{~mL}$ hydrochloric Acid ( $\mathrm{HCl})+20 \mathrm{~mL} \mathrm{HNO} 3)$. The microstructure of the AISI 304 workpiece was characterized using a Nikon ECLIPSE IV 100 equipped with UC30 camera, see Figure 1. The turning process was performed using a Nakamura-Tome Sc-450 lathe. The cutting tool (Manufacturer: Kennametal) used for the experiments was an uncoated cemented carbide insert with $\mathrm{WC} / 6 \% \mathrm{Co}$. The designation of the insert is ISO WNMG432-SM with the following geometry characteristics: back rake angle, $\lambda 0=7^{\circ}$; clearance angle, $\alpha 0=0^{\circ}$; wedge angle, $\beta=82^{\circ}$; edge radius, $\mathrm{r}=34 \mu \mathrm{m}$ and nose radius, $\mathrm{R} \varepsilon=0.8 \mathrm{~mm}$. Tool-holder used for high pressure cooling was an ISO PWLNR 16-4DHP with three cooling nozzles used, supplied by Sandvik (Figure 2). The high pressure coolant was applied at a flow rate of 30 $\mathrm{L} / \mathrm{min}$ via three nozzles directed toward the rake face of the 
cutting tool at a pressure of 70 bar. The cutting fluid chosen was semi-synthetic coolant-CommCool тм 8800, manufactured by the Wallover Company (Harrow, ON, Canada), at a concentration of $7 \%$, typically used with stainless steel alloys.

Table 1: Chemical composition and mechanical properties of AISI 304. [7]

\begin{tabular}{|c|c|c|c|c|c|c|c|}
\hline \multicolumn{1}{|c|}{ Chemical Composition \% } \\
\hline $\boldsymbol{C}$ & $\boldsymbol{S i}$ & $\boldsymbol{M n}$ & $\boldsymbol{p}$ & $\boldsymbol{S}$ & $\boldsymbol{C r}$ & $\boldsymbol{N i}$ & $\boldsymbol{N}$ \\
\hline 0.08 & 0.75 & 2.0 & 0.045 & 0.03 & 20 & 0.50 & 0.1 \\
\hline
\end{tabular}

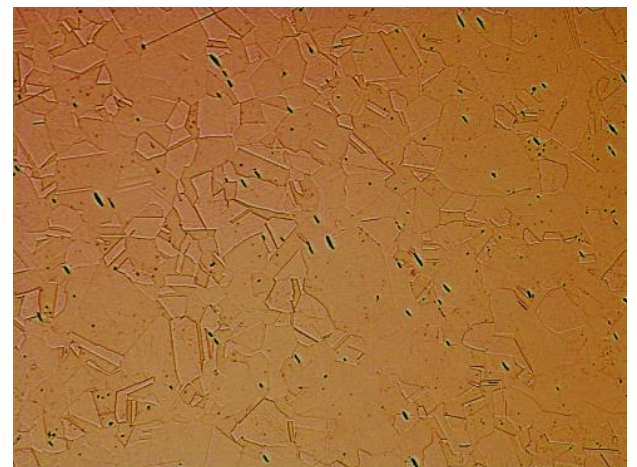

Figure 1. The microstructure of AISI 304 with an austenitic structure.

The investigations have been performed with respect to varied cutting speed $(60-100-150 \mathrm{~m} / \mathrm{min})$, feed rate $(0.1-0.2-$ $0.3 \mathrm{~mm} / \mathrm{rev}$ ) and cutting conditions (Dry-Convention coolant HPC). During turning operation the depth of cut was kept constant at $0.5 \mathrm{~mm}$ and a new tool insert was used for each run for all the machining runs.

The tool flank wear was measured using a KEYENCE VHX 5000 digital microscope, equipped with a CCD camera and image analyzer software. The tool life criterion was set to a flank wear of $0.3 \mathrm{~mm}$ according to the recommendation of the ISO 3685 Standard [8]. During the tests, the cutting tools were analyzed by SEM, using a Vega 3-TESCAN.

The chip compression ratio, the shear angle and the friction coefficient at the tool-chip interface were determined using standard methods [9]. The surface roughness of the machined workpiece was measured across the tool feed direction by means of an Alicona Infinite Focus-with the Profile roughness module. The procedures of surface roughness measurements were performed according to EN ISO standard 25178 [10]. Roughness measurements were taken with a cut-off wave length of $800 \mu \mathrm{m}$, a vertical resolution of $100 \mathrm{~nm}$ and a lateral resolution of $2 \mu \mathrm{m}$.

During the machining tests, the cutting force and chip-tool interface temperature measurements were performed with a 3D component tool holder Kistler dynamometer type with a data acquisition system and thermocouple sensors, respectively. The signals of the forces from the dynamometer were transmitted to a Kistler 5010 type amplifier, and then recorded on a computer using LABVIEW version 14.0 software. To measure chip-tool interface temperature, thermocouple placed just right side of insert through hole made at right side of shim. The signals of the temperature from the thermocouple were transmitted to analog K-type thermocouple amplifier, and then recorded on a computer using LABVIEW version 14.0 software.

(a) (b)

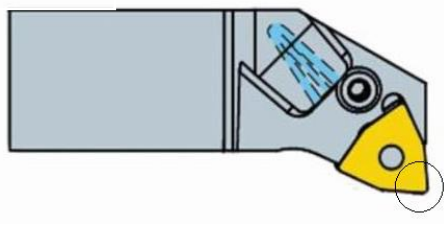

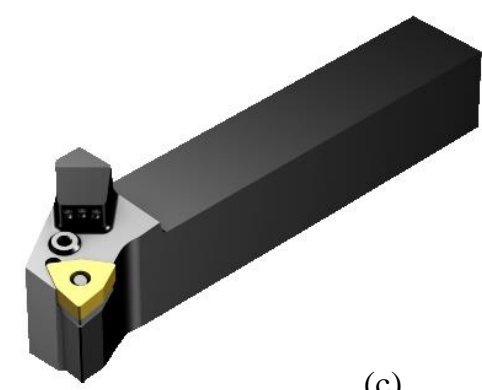

(c)

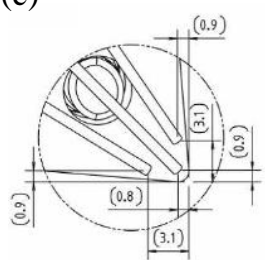

Figure 2.(a) High pressure coolant tool holder (b) concentrated flow cooling in and (b) destination of the flow cooling on the inserts [11]

\section{RESULS AND DISCUSSION}

\section{A. Effect of High Pressure coolant on Machining Temperature}

In this section, an investigation of effect of HPC on machining temperature are discussed. Figure 3 shows the interface of chip-tool and the direction of applied jets. Fluid jets are aimed at chip-tool interface in order to remove the originated heat [12]. The HPC when passed through a small diameter of jet opening produces high volumetric flow rate, which creates a thin boundary layer on impingement surface, and thus enhances heat transfer rate.

In this study, very high velocity of fluid jet induced by high pressure (70 bar) and small nozzle diameter $(1 \mathrm{~mm})$ enhance convective heat transfer rate [13]. Accordingly, three turbulent flows acting on the mutually perpendicular surfaces effectively control the cutting temperature by facilitating rapid removal of heat. The heat transfer rate can be enhanced if the jet impinges in the maximum temperature region of the cutting tool.

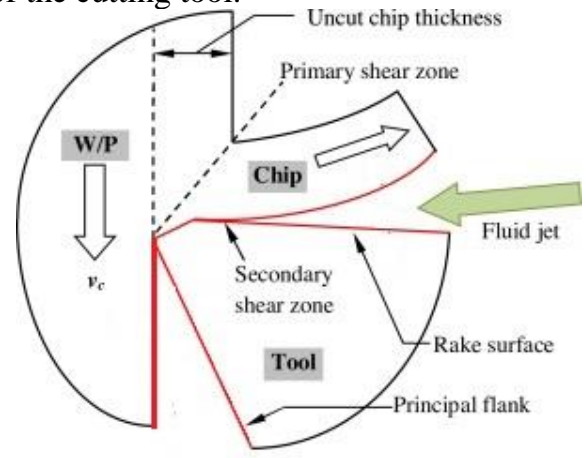

Figure 3: Chip-tool interface and the direction of applied jets [12].

Figure 4a exhibits the movement of chip-tool interface temperature with cutting speed at different feed rates. As it is shown, higher cutting speed is affiliated with elevated 
temperature which was expected owing to the dominant nature of endured friction by extended chip-tool contact area [14]. At the same time, the effect of higher feed rate is reflected by an increase in chip-tool interface temperature. This is endorsed to a higher rate of conversion of mechanical to thermal energy by the chip evolution by shearing of solid material [15]. Therefore, the recommended speed is $60 \mathrm{~m} / \mathrm{min}$ along with $0.1 \mathrm{~mm} / \mathrm{rev}$ feed rate to originate the minimum temperature of $22.5{ }^{\circ} \mathrm{C}$ under the employment of effective HPC jets.

Figure $4 \mathrm{~b}$ shows the typical temperature profiles of toolchip interface with machining time for dry cut, conventional coolant, and HPC at the recommended speed and feed. Temperature profiles for dry cut show gradual increase of temperature with machining time. Maximum temperature rise for dry cut is $140^{\circ} \mathrm{C}$, for conventional coolant is $36^{\circ} \mathrm{C}$, and for HPC is $22^{\circ} \mathrm{C}$ for the optimum cutting condition. HPC decreases the tool-chip temperature by $38 \%$ in comparison with conventional coolant and by $85 \%$ in comparison with dry cut indicating better cooling effect. Above results clearly indicate the effectiveness of HPC in reducing the temperature. This is endorsed to a higher rate of conversion of mechanical to thermal energy by the chip evolution by shearing of solid material [16].
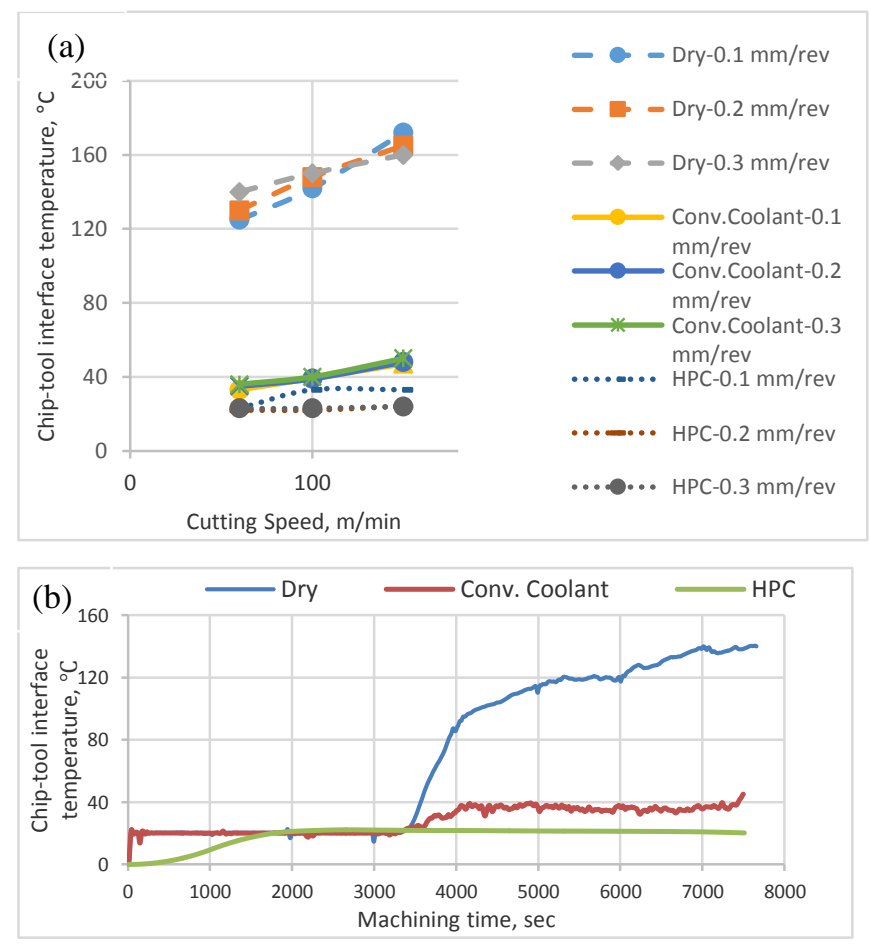

Figure 4: (a) chip-tool interface temperature values at different cutting conditions and corresponding chip-tool interface temperature profiles at optimum cutting conditions.

\section{B. Effect of High Pressure Coolant on Machining Performance}

Force components are almost always utilized to determine chip formation process of engineering materials. Although measuring forces directly help to determine power requirement for cutting the work material, it is also useful to interpret the whole cutting process [17]. The main cutting forces for the dry and two different cooling at optimum cuing conditions is depicted in Figure 5. As shown, main cutting forces are higher with dry and conventional coolant as compared to HPC. The reduction in the cutting force with HPC could be due to several reasons. HPC jet strikes the chip at a point very close to the cutting edge of insert, resulting in the reduction of the width of the chip. Consequently, the tool chip contact area on the rake face is reduced, which reduces the friction between insert and chip and eventually reduces cutting force. Another reason is that HPC is able to penetrate deeper into the cutting interface, thus providing more efficient cooling as well as lubrication [18-19]. The coolant water wedge created at the tool-chip interface reduces tool-chip contact length and forces, which can be also connected to benefits in friction conditions.

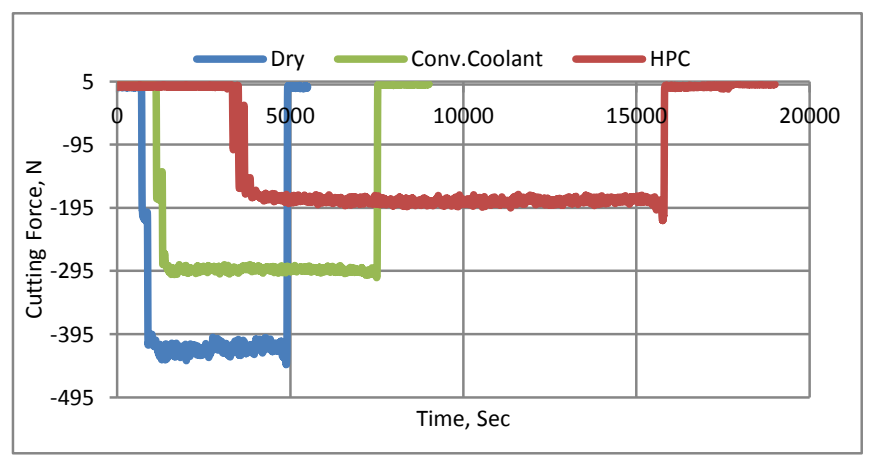

Figure 5: Main cutting forces for dry, conv. coolant and HPC at optimum cutting conditions.

The average surface roughness parameter $(\mathrm{Ra})$ has been studied and its behavior with the progression of cutting speed at different feed rates for dry, conventional coolant, and HPC is described in Figure 6a. It is evident from this figure that a reduced roughness is achieved at higher cutting speed. On the contrary, the sliding and adhesion of chips at low spindle speed are accounted for high surface roughness [20]. Also, the surface roughness is increased by the feed rate as a result of the straining effect of high feed rate [19].

In addition, in all the cases, best surface finish is obtained with HPC, followed by conventional coolant and then dry cut, see Figure 6b. When chipping occurs as it is shown in dry condition, the surface obtained is the worst and shows very high value of average surface roughness because of melting of chips on the workpiece surface. The improvement of surface finish with the use of HPC may be because of tool wear rate becomes slower. 
(a)

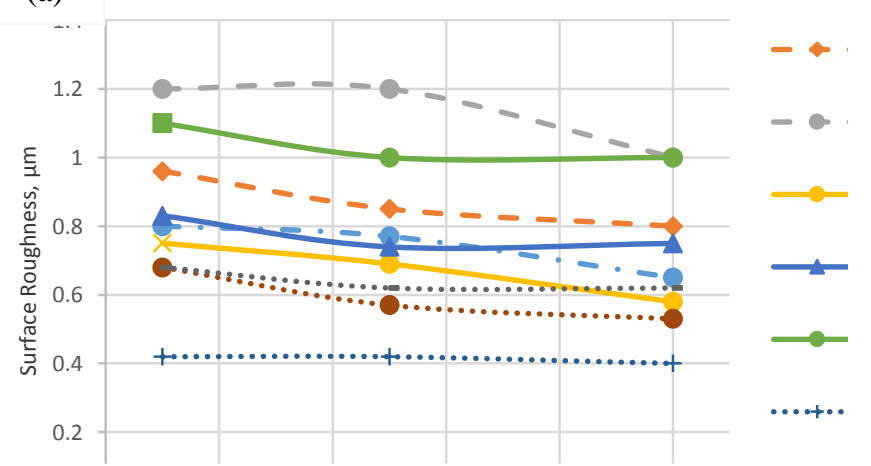

(b)

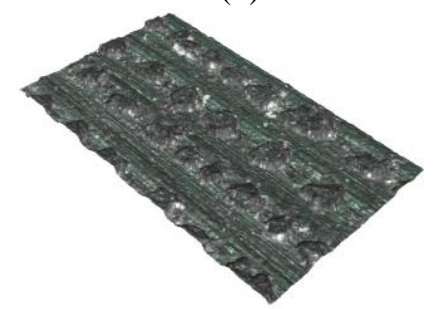

(d)

(c)

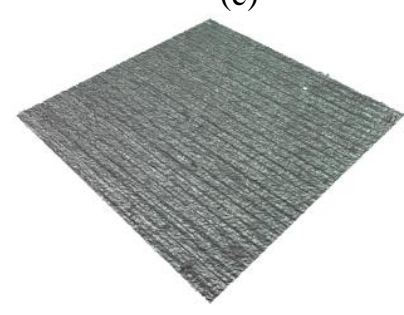

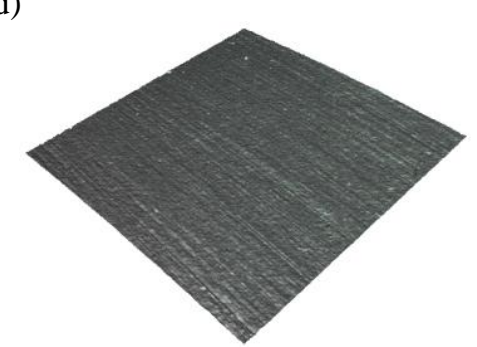

Figure 6: (a) average surface roughness at different cutting conditions and corresponding machined surface for (b) dry, (c) conv. coolant and (d) HPC at optimum cutting conditions.

To study the effectiveness of HPC, the chips were collected and presented in Figure 7. Although continuous and snarled chips are produced under dry and conventional coolant conditions, tubular chips are produced under HPC condition. HPC condition helps to break chips, in particular at lower feed rate by producing shorter tubular chips. In contrast, conventional coolant didn't show distinct effect on chip breakability. Under dry and conventional coolant, chip fracture is due to the negative bending moment created by an obstruction. However, effective chip breaking under HPC is due to the mechanical action of the high pressure jet. The 70 bar coolant pressure is equivalent to a force of approximately $70 \mathrm{~N}$ (assume that an area of $1 \mathrm{X} 1 \mathrm{~mm}^{2}$ ) on the chip which is large enough to fracture the chip by a positive bending moment, before making contact with an obstruction.

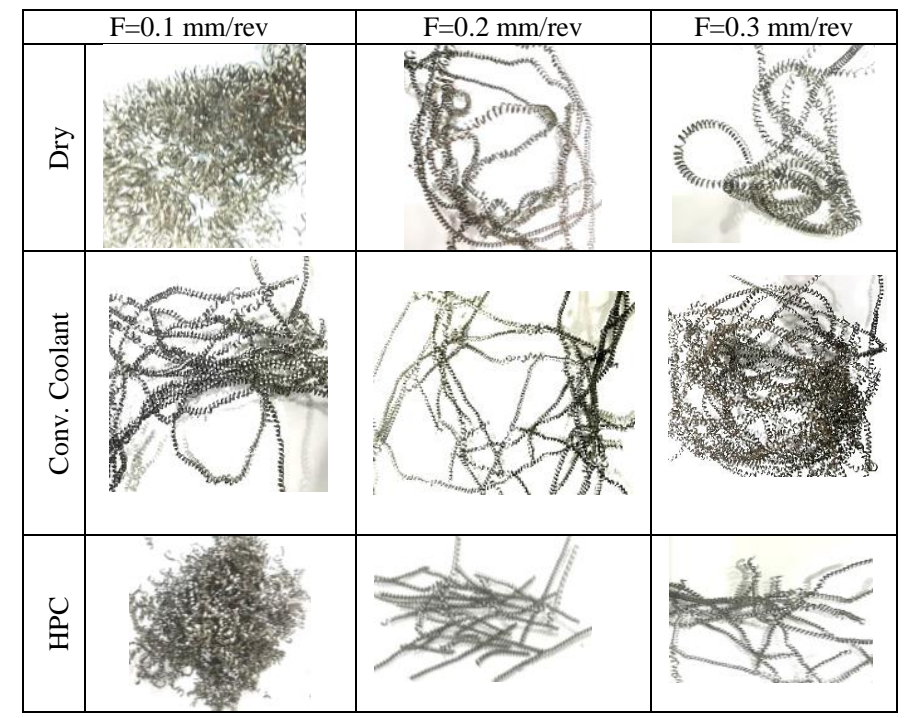

Figure 7: Chip breaking under various various cutting conditiond and feed rates.

Figure 8 shows tool life of carbide inserts with variation of cutting speed and feed rate, respectively. From these figures, HPC is found to be most effective for the cutting conditions of $f=0.1 \mathrm{~mm} / \mathrm{rev}$ and $v=150 \mathrm{~m} / \mathrm{min}$, which is considered as optimum cutting condition for this high pressure system. Experiments have been carried out by varying speed and feed rate, however one parameter is varied while other two are kept constant at optimum value and thus, effective zones of HPC are identified. At lower speed below $150 \mathrm{~m} / \mathrm{min}$, the use of HPC is not effective as high speed. At higher speeds, inserts fail due to chipping and excessive flank wear for dry cut and conventional coolant whereas only progressive flank wear is observed for HPC. HPC is also found to be very effective at lower feed rate $(0.1 \mathrm{~mm} / \mathrm{rev})$, reducing the chipping of inserts, which is observed for both dry cut and conventional coolant. In contrast at higher feed rate $(0.3 \mathrm{~mm} / \mathrm{rev})$, the use of HPC is found to be non-effective. The reasons for that is at lower feed rate, the generation of heat is low and the temperature rise in insert is also low and when the HPC is used, different modes of heat transfer take place. First film boiling starts and persists for very short time. Then vigorous nucleate boiling starts and then forced convection takes place [21]. At lower feed rate, pressure is high enough to remove the heat from the cutting zone. But when the feed rate is high, the temperature rise in the insert is high and film boiling persists for longer time and nucleate boiling may not take place [18]. As a result, no phase change takes place to reduce temperature. For this reason, the temperature rise causing chipping. 


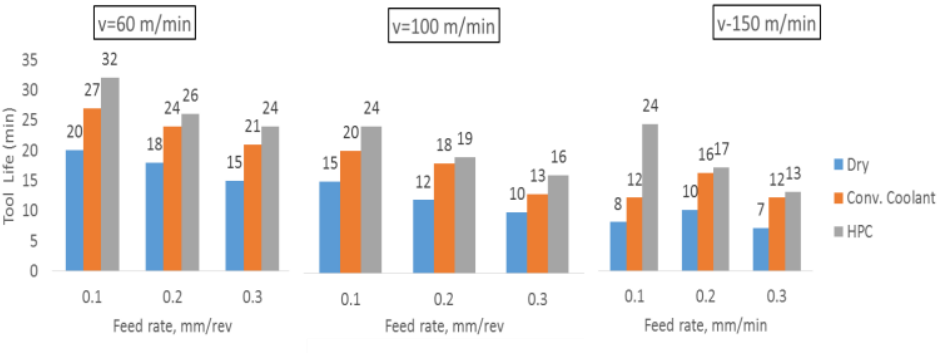

Figure 8. Recorded tool lives at various cutting conditions under dry, conv.coolant, and HPC.

Figure 9 shows SEM images of worn inserts at optimum cutting condition $(150 \mathrm{~m} / \mathrm{min}, 0.1 \mathrm{~mm} / \mathrm{rev})$. It is clear from the SEM pictures that inserts fail because of chipping for both dry cut and conventional coolant and largest wear zone is observed for dry cut, followed by conventional coolant. No chipping is observed for HPC and wear zone is also the smallest. Also, SEM analysis of the worn inserts show a smooth pattern in dry and conventional coolant conditions, indicating that diffusion wear mechanism is predominant. Diffusion wear is mostly dependent on the temperature at the interface. The HPC system has been to significantly reduce the temperature of the cutting tool which in turn reduces the diffusion wear rate (Figure 9c) and consequently increases tool life.
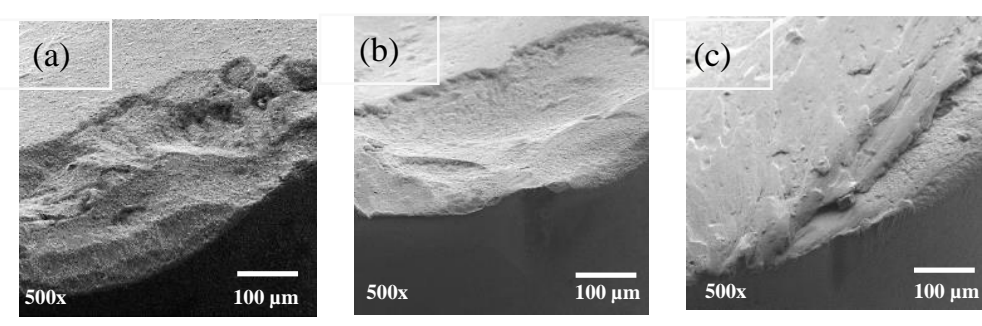

Figure 9. SEM images of worn inserts at optimum cutting conditions under (a) dry, (b) conv.coolant, and (c) HPC.

\section{ACKNOWLEDGMENT}

The authors would like to gratefully acknowledge the financial supported from the Natural Sciences and Engineering Research Council of Canada's (NSERC) Strategic Canadian Network for Research and Innovation in Machining Technology (CANRIMT).

\section{REFERENCES}

[1] M.B. Guemmour, A. Sahli, S. Kebdani and Sara Sahli, "Simulation of the Chip Formation and Temperature Distribution by the Fem," Journal of Applied Sciences, vol.15, pp.1138-1148, 2015.

[2] W.Akhtar, J. Sun, P. Sun, W. Chen, and Z. Saleem, "Tool wear mechanisms in the machining of Nickel based super-alloys: A review, " Frontiers of Mechanical Engineering, vol.9. pp. 106-119, 2014.

[3] M. Kamruzzaman and N. R. Dhar, "The Influence of High Pressure Coolant on Temperature Tool Wear and Surface Finish in Turning
17 crnimo6 And 42crmo4 Steels," ARPN Journal of Engineering and Applied Sciences, vol. 4, no. 6, 2009.

[4] R. A. Mahdavinejad and S. Saeedy, "Investigation of the influential parameters of machining of AISI 304 stainless steel," Sadhana, vol. 36, Part 6, pp. 963-970, 2011.

[5] H. Sharma and M. Sharma, "Influence of Cutting Fluids on Quality and Productivity of Products in Manufacturing Industrie," International Journal of Engineering, Management and Sciences, vol. 1, pp.8-11, 2014.

[6] [6] A.R Natasha, J. A. Ghani, C. H. Che Haron, and J. Syarif, "Temperature At The Tool-Chip Interface In Cryogenic And Dry Turning Of Aisi 4340 Using Carbide Tool," Int j simul model vol. 15, pp. 201-212, 2016.

[7] ISO 15510-Stainless steels-Chemical composition: Annex C: classification of grades, c.1: stainless steels; International Organization for Standardization: Geneva, Switzerland, 2014.

[8] ISO 3685-Tool Life Testing with Single-Point Turning Tools, 2nd ed.; International Organization for Standardization: Geneva, Switzerland, 1993. (Revised in 2018).

[9] Shaw, M. Metal cutting principles, second ed.; Oxford University Press: New York, 2005

[10] ISO 25178-2 Geometrical Product Specifications (GPS) -Surface Texture: Areal Part 2: Terms, Definitions and Surface Texture Parameters; International Organization for Standardization: Geneva, Switzerland, 2012.

[11] R. Drlička, V. Kročko, and M. Matúš, "Machinability improvement using high-pressure cooling in turning," vol. 60, pp.70-76, 2014.

[12] L. Liang, Y.Quan, and Z. Ke, "Investigation of tool-chip interface temperature in dry turning assisted by heat pipe cooling," Int J Adv Manuf Technol, vol. 54, pp.35-43, 2011.

[13] V. Katti, S. Prabhu, "Experimental study and theoretical analysis of local heat transfer distribution between smooth flat surface and impinging air jet from a circular straight pipe nozzle,". Int. J. Heat Mass Transfer, vol.51, pp.4480-4495, 2008.

[14] E. Ezugwu, J. Bonney, "Finish machining of nickel-base Inconel 718 alloy with coated carbide tool under conventional and high-pressure coolant supplies," Tribol. Trans., vol.48, pp.76-81, 2005.

[15] S. Cedergren, G. Petti, and G. Sjöberg, "On the Influence of Work Material Microstructure on Chip Formation, Cutting Forces and Acoustic Emission When Machining Ti-6Al-4V, " Procedia CIRP, vol.12, pp.55-60, 2013.

[16] T. Öpöz, X.Chen, "Chip Formation Mechanism Using Finite Element Simulation," Journal of Mechanical Engineering, vol. 62, pp. 11-22, 2016.

[17] M. Miaa, N. R. Dharb, "Effects of duplex jets high-pressure coolant on machining temperature and machinability of Ti-6Al-4V superalloy," Journal of Materials Processing Tech., vol. 252, 688-696, 2018.

[18] A. Kumar , G. Singh , S.S Gill, "Impact Of Varying The Nozzle Stand Off Distance On Cutting Temperature In Turning Of En-31 Steel With Minimum Quantity Lubrication," International Journal of Research in Engineering and Technology, vol.2, pp.931-936, 2013.

[19] M. Kamruzzamam and N.R. Dhar "The effect of high Pressure Coolant (HPC) Jet in Machining of 42CRMO4 Steel by Uncoated Carbide Inserts", Journal of Mechanical Engineering, vol.39, p.71-77, 2008.

[20] T. Bouchnak, A. Morel, and B. Furet, "Influence Of High-Pressure Coolant Assistance On The Machinability Of The Titanium Alloy Ti555-3," Machining Science and Technology, vol.19, pp.134-15,2015.

[21] A. Senthil Kumar, M. Rahman and S. L. Ng, "Effect of High-Pressure Coolant on Machining Performance, " Int J Adv Manuf Technol, vol.20, pp.83-91, 2002 